\title{
Past the postauricular graft
}

\author{
MSG Bell MD
}

$\mathrm{O}$ ne preferred technique to replace lost skin on the face is to use a full-thickness postauricular skin graft.

Many years ago, when requiring a full-thickness skin graft after removal of a large skin cancer on an older lady, I noted that when she was lying down she had a remarkable amount of excess skin in the preauricular area. She had a rather stiff neck, and it seemed that taking a postauricular skin graft would aggravate her stiff neck, and perhaps mine as well.

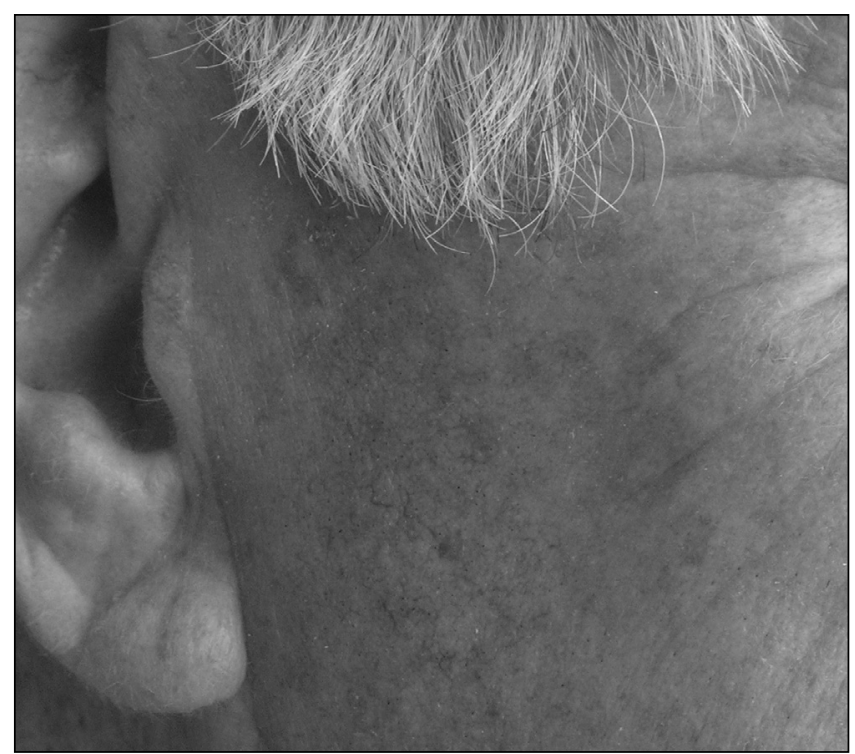

Figure 1) Photograph of the preauricular area that may potentially be used as a full-thickness skin graft donor site
I therefore took a preauricular skin graft, marking an ellipse as required. I incised through the skin, barely into the dermis, and removed the graft quite readily with a number 10 blade, much as one would de-epithelialize the area around a nipple with a breast reduction.

The skin taken required no further modification, and was simply used in the defect left by removal of the tumour.

Closure of the donor site was readily accomplished by excising the residual elements of dermis and some fat. A subcuticular

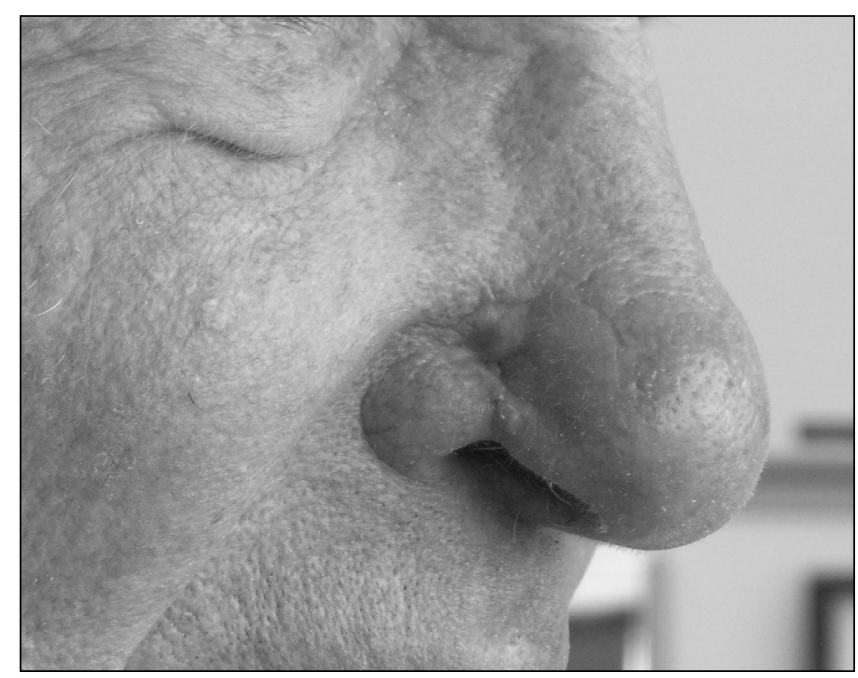

Figure 2) Recurrent basal cell carcinoma requiring a full-thickness skin graft

\footnotetext{
The Ottawa Hospital, Ottawa, Ontario

Correspondence and reprints: Dr Michael Bell, The Ottawa Hospital, 402 - 1919 Riverside Drive, Ottawa, Ontario K1H 1 A2.

Telephone 613-739-5424, fax 613-739-7168, e-mail msgbell@cyberus.ca
} 


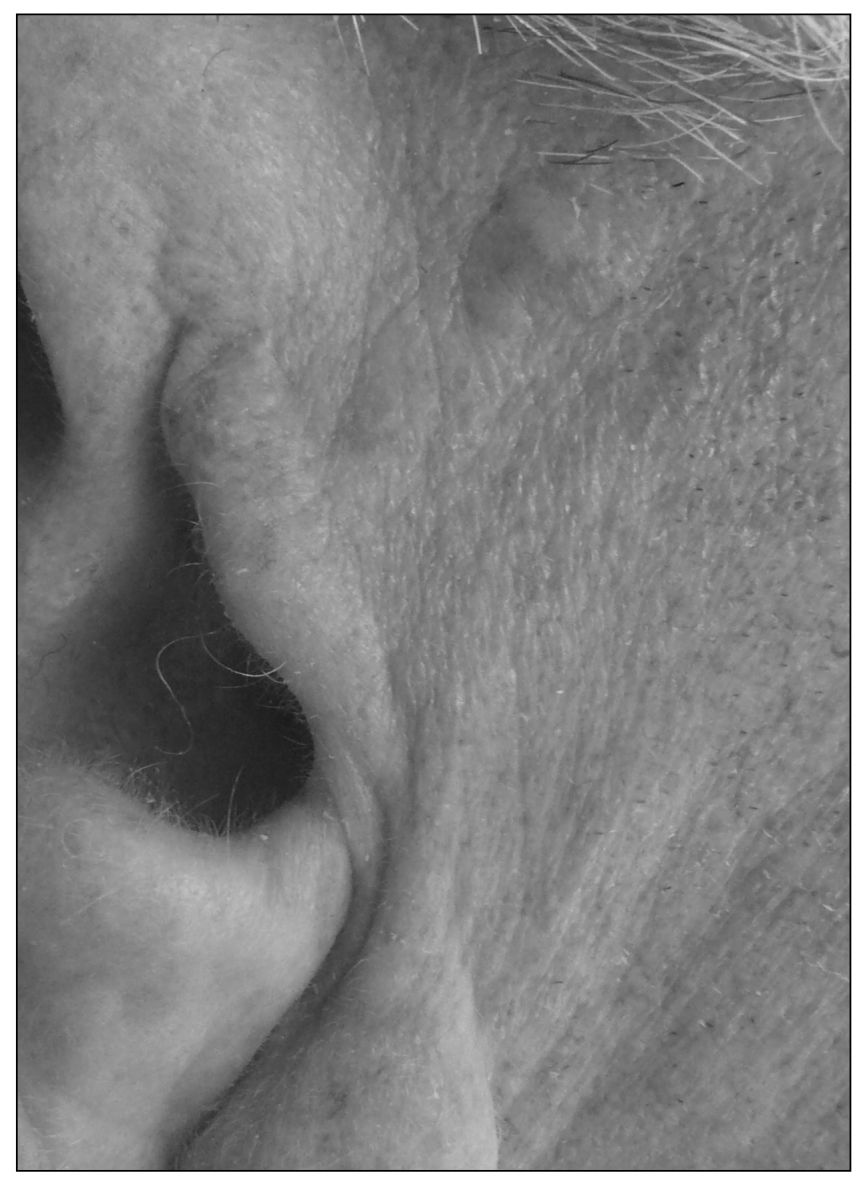

Figure 3) Typical donor site two months postoperatively

repair was readily performed, which turned out to leave an indiscernible mark, much as with a facelift incision. Her only complaint was that the donor site cheek looked so much better than her opposite cheek because the skin had been tightened to an extent that made her look somewhat younger.

I have continued to use the preauricular skin graft as the procedure of choice for full-thickness skin grafts on the face since that time. I find the skin is in fact superior in quality to the postauricular graft. The donor site scar is minimal, because the typical person requiring a graft of this sort usually has a significant excess of skin on the cheek. The donor site

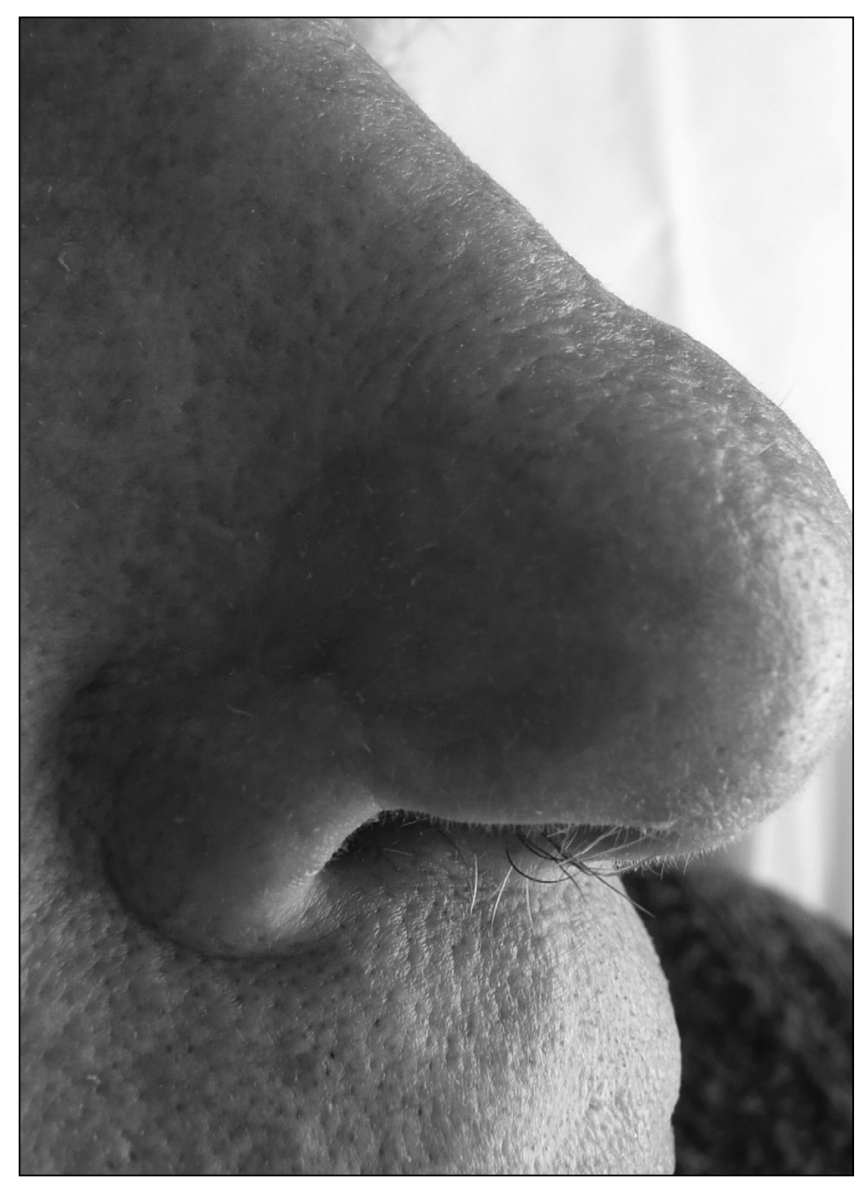

Figure 4) Typical recipient site two months postoperatively

morbidity is also much reduced. With the traditional postauricular skin graft, the patient's glasses often irritate the incision line. The largest area I have taken to date measures $55 \mathrm{~mm} \times 25 \mathrm{~mm}$. I also have found that the time required to peform this procedure is about one-half of that required to harvest postauricular skin.

A typical donor and recipient site are shown at two months postoperatively (Figures 3 and 4).

In summary, a preauricular skin graft, in my opinion, has many advantages and is much less of a pain in the neck for all concerned. 